
\title{
Preliminary Measurements of Gamma Ray
Effects on Characteristics of Broad-Band GaAs
Field-Effect Transistor Preampliflers
}

H.G. Jackson, T.T. Shimizu, and B. Leskovar

\author{
Lawrence Berkeley Laboratory \\ University of California \\ Berkeley, California 94720
}

January 1985

\section{DISCLAIMER}

This report was prepared as an account of work sponsored by an agency of the United States Government. Neither the United States Government nor any agency thereof, nor any of their employees, makes any warranty, express or implied, or assumes any legal liability or responsibility for the accuracy, completeness, or usefulness of any information, apparatus, product, or process disclosed, or represents that its use would not infringe privately owned rights. Reference herein to any specific commercial product, process, or service by trade name, trademark, manufacturer, ot otherwise does not necessarily constitute or imply its endorsement, reconmendation, or favoring by the United States Government or any agency thereof. The views and opinions of authors expressed herein do not necessarily state or reflect those of the United States Government or any agency thereof.

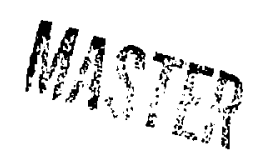




\author{
PRELIMINARY MEASUREMENTS OF GAMMA RAY \\ EFFECTS ON CHARACTERISTICS OF BROAD-BAND GaAS \\ FIELD-EFFECT TRANSISTOR PREAMPLIFIERS \\ H.G. Jackson, T.T. Shimizu and B. Leskovar \\ January 25, 1985
}

\begin{abstract}
The effect of gamma radiation on electrical characteristics of cryogenically cooled broad-band low-noise microwave preamplifiers has been preliminarily evaluated. The change in the gain and noise figure of a 1-2 GHz preami lifier using GaAs microwave transistors was determined at gamma doses betweer $10^{5} \mathrm{rad}$ to $5 \times 10^{8} \mathrm{rad}$. The gain and noise figure was measured at ambient te:peratures of $300 \mathrm{~K}$ and $80 \mathrm{~K}$.
\end{abstract}

\title{
INTRODUCTION
}

The stochastic beam-cooling experiments at Fermi National Accelerator Laboratory required the development of two types of low-noise microwave preamplifiers.[1] While each preamplifier has a gain of $>30 \mathrm{~dB}$, one has a band-width of 1-2 GHz[2] and the other covers 2-4 GHz.[3] For low noise, the preamplifiers are operated at an ambient temperature of $80 \mathrm{~K}$. Also, they are located inside the beam tank about $30 \mathrm{~cm}$ off of the bean line. Twelve of the 1-2 $\mathrm{GHz}$ units are distributed around the Accumulator Ring, and eight of the 2-4 GHz units are in the Debuncher Ring.

There is the possibility that during beam tuning the beam will strike the pick up electrode and other components in the vicinity of the preamplifiers. This will probably give rise to a multitude of strange particles, including gamma rays. With no ready source of high energy protons available we have been unable to investigate the effect on the preamplifiers of such a source. However, we did have access to a multicurie $6 b_{\text {co }}$ source. We were, therefore, able to perform a series of experiments on the total gamma ray dose effects on the preamplifiers.

The design of the preamplifiers is similar, consisting of a cascade of Mitsubishi MGF 1400-series GaAs field-effect transistors (three for the 1-2 GHz amplifier and four for the 2-4 GHz unit). The preamplifiers are made with packaged devices and lumped components, housed in a gold-plated copper enclosure about $3^{\prime \prime L} \times 2^{\prime \prime} \mathrm{W} \times 1 " \mathrm{H}$. Ceramic chip capacitors are used extensively for RF by-passing and coupling. Chip resistors are also used. Simple air-core inductors are used, wound with $0.25 \mathrm{~mm}$ diameter gold-plated phosphor-bronze wire. Discrete metal-film resistors are used in the bias networks of each transistor. The transistors are mounted in air, but the basic substrate of thi: preamplifier is Rogers RT/duroid 5880. RT/duroid 6010 material is used for the input transmission line of the preamplifier. 
A survey of the literature indicated that 60 Co radiation on discrete GaAs FET devices caused only relatively small changes in the threshold voltage and carrier mobility at $10^{8}$ rad, provided the channel doping level is about $10^{17} \mathrm{~cm}^{-3}$; however, at a doping level of $10^{16} \mathrm{~cm}^{-3}$, significant changes were seen at $10^{7} \mathrm{rad}$.[4] Also, GaAs microwave FETs have retained functionality up to $10^{8}$ rad or more, although RF gain[5] and noise figure[6] begin to degrade between $10^{7}$ and $10^{8} \mathrm{rad}$. Radiation effects on the passive components of the preamplifier were expected to be minimal.

\section{PROCEDURE}

The source of our irradiations was an array of 16 60 Co capsules equally spaced around the circumference of a 3.1" diameter circle. The sample huider was at the center of this circle, and rotated at about $2 \mathrm{rpm}$. A production type version of a 1-2 GHz preamplifier, unpowered and at room temperature, was placed in the sample holder. The radiation dose varied from $10^{5}$ to $5 \times 10^{8}$ rad. The dose rate was about $0.7 \mathrm{M} \mathrm{rad} / \mathrm{hr}$., so that the irradiation times varied from 8 minutes to 26 days.

At the conclusion of each irradiation, a room temperature $(300 \mathrm{~K})$ measurement was made of the gain characteristic of the preamplifier, followed by a measurement of the noise figure. These measurements were completed with in one hour of removing the preamplifier from the gamma ray source. The preamplifier was then placed in a cryostat. Unfortunately, about 24 hours then elapsed before the preamplifier was at the operating cold temperature of $80 \mathrm{~K}$. Over $\mathrm{s}$ : period of four hours, three measurements were made of the yain characteristic and noise figure at the cold temperature. The temperature in the cryostat was then allowed to rise; about 16 hours elapsed before the room temperature mieasurements were repeated one more time.

\section{RESULTS}

Figure 1 shows the gain characteristic at $300 \mathrm{~K}$ and $80 \mathrm{~K}$, with the radiation dose as the variable. Since the data from the two $300 \mathrm{~K}$ measurements, one before cooling, the other after, were within experimental error $(\sim 0.2 \mathrm{~dB})$, the average value has been plotted on the graph. Similarly, there was little difference in the three $80 \mathrm{~K}$ measurements, hence the graph shows the average value. The graph for $10^{5}$ rad is essentialily that of the characteristic before irradiation. The data, at both temperatures, indicates a small but steady increase in gain with radiation doses up to $10^{8}$ rad. But then, after a dose of $5 \times 10^{8}$ the gain had dropped considerably.

The noise figure data is presented in Fig. 2. Again, generally, the two sets of measurements at $300 \mathrm{~K}$, and the three at $80 \mathrm{~K}$, were within experimental error $(\sim 0.1 \mathrm{~dB})$. The average value has therefore been used in the graphs. At both temperatures, the data indicates some increase in the noise figure with increasing radiation doses, with an exceptionally large increase after

$5 \times 10^{8} \mathrm{rad}$. It should be noted, that only after the $10^{8}$ irradiation was the $300 \mathrm{~K}$ noise figure data measurably less (about $0.4 \mathrm{~dB}$ ) after cooling than before. The after cooling data is given in the figure.

No catastrophic failures were noted until after the $5 \times 10^{8}$ irradiation, when it was found that the $51.1 \Omega$ metal-film resistor in the drain lead of the second transistor was open-circuit. It was replaced. A measurement of all the 
other resistors revealed the $50 \Omega$ chip resistor in the drain lead of the first transistor to be double its nominal value. It was not replaced. Further, it was after the $5 \times 10^{8}$ irradiation that it was found the teflon insert of the power connector on the preamplifier box was close to deterioration. It had to be replaced. It was also noted at this time that the adhesion of the copper to the circuit board was quite loose. This was not the case initially.

\section{CONCLUSIONS}

At the two temperatures of $300 \mathrm{~K}$ and $80 \mathrm{~K}$, the gain characteristic and noise figure of the preamplifier are relatively unchanged at a gamma fluence of up to $10^{8}$ rad. However, the increase in gain with increasing doses was not eipected. The decrease in gain and substantial increase in noise figure at $5 \times 10^{8}$ would indicate this as an upper limit for gamma irradiation of this preamplifier. This conclusion is further sustained by the deterioration of the printed circuit board and teflon insert used in this preamplifier.

The decrease in the noise figure measured at $300 \mathrm{~K}$ following the cold period, after the $10^{8}$ rad irradiation, does give some evidence of anriealing. But further experiments are required to really justify this.

The open-circuit metal-film resistor and the change in resistance of the chip resistor were not expected, and maybe only coincidental.

It must be noted that these conclusions are the result of just one series of gamma irradiations on one particular broad-band microwave preamplifier unit. Furthermore, the incidence of high energy protons and other particles on the preamplifier would undoubtedly yield results of a much more critical nature.

In addition to the investigation of permanent damage arising from cumulative ionizing radiation exposure to gamma rays, electrons, and protons, the permanent damage from neutron exposure should also be studied. High energy neutron irradiation of discrete GaAs field-effect transistors show that the onset of parameter degradation occurs in the $10^{14}$ to $10^{15} \mathrm{n} / \mathrm{cm}^{2}$ range; however, at an optimum channel doping density of $1017 / \mathrm{cm}^{3}$, changes were small after $10^{15} \mathrm{n} / \mathrm{cm}^{2} .[4,6]$ The principal FET parameters that are affected are the pinchoff voltage $\left(v_{p}\right)$, the maximum driin current $\left(I_{0}\right)$, the maximum transconductance $\left(g_{\mathrm{mo}}\right)$, and the cut-off frequency $\left(f_{c}\right)$. In general, all decrease monotonically with increasing neutron fluences. [4]

Another area of study, especially for pulsed-beam applications, is the transient radiation effects in these FET's. Irradiation of the devices at a low level (<200 rads) with $x$-ray beanis (3-60 ns wide), result in large changes in the drain current for times varying from <100 ns [7] to $>10 \mathrm{s.[8]}$

Since the magnitude of all these effects has been shown to vary widely among GaAs devices, even among devices of the same type but of a different production lot, further investigations are necessary to establish the suitability of these devices for the stochastic beam-cooling systems and feedback systems of high energy storage rings. 


\section{ACKNOWLEDGMENT}

This work was performed as part of the program of the Electronics Research and Development Group of Lawrence Berkeley Laboratory, University of California, Berkeley, and was supported by the Office of High Energy and Nuclear Physics of the U.S. Department of Energy under Contract No. DE-AC03-76SF00098. The authors would like to express their appreciation to Dick Lemmon for his ready cooperation and assistance in using the ${ }^{60} \mathrm{Co}$ source.

Reference to a company or product name does not imply approval or recommendation of the product by the University of California or the U.S. Departinent of Energy to the exciusion of others that may be suitable. 
1. The Fermi Laboratory Tevatron 1 Project Design Report, Fermi National Accelerator Laboratory, Batavia, 111. (September 1984).

2. C.C. Lo and B. Leskovar, Cryogenically Cooled Broadband GaAs Field-Effect Transistor Preamplifier, IEEE Trans. Nucl. Sci., NS-31, p. 474 (1984).

3. H.G. Jackson and T.T. Shimizu, A Low-Noise 2-4 GHz Preamplifier, Nucl. Instr, and Meth. 226, p. 560 (1984).

4. R. Zuleeg and K. Lehovec, Radiation Effects in GaAs Junction Field-Effect Transistors, IEEE Trans. Nucl. Sci., NS-27, p. 1343 (1980).

5. D.M. Newell, P.T. Ho, R.L. Mencik and J.R. Pelose, Total Dose Hardness of Microwave GaAs Field-Effect Transistors, IEEE Trans. Nucl. Sci., NS-28, p. 4403 (1981).

6. R.J. Gutman and J.M. Borrego, Degradation of GaAS MESFET in Radiation Environments, IEEE Trans. on Rel., R-29, p. 232 (1980).

7. J.G. Castle, Jr., M.G. Armendariz, D.R. Smith and G.R. Schuster, Transient Response of a Small-Signal Microwave GaAs FET to X-Rays, IEEE Trans. Nucl. Sci., NS-31, pp. 1596-1598 (December 1984).

8. W.T. Anderson, Jr. and S.C. Binari, Transient Radiation Effects at X-Band in GaAs FETs and ICS, IEEE Trans. Nucl. Sci., NS-30, No. 6 (1983). 

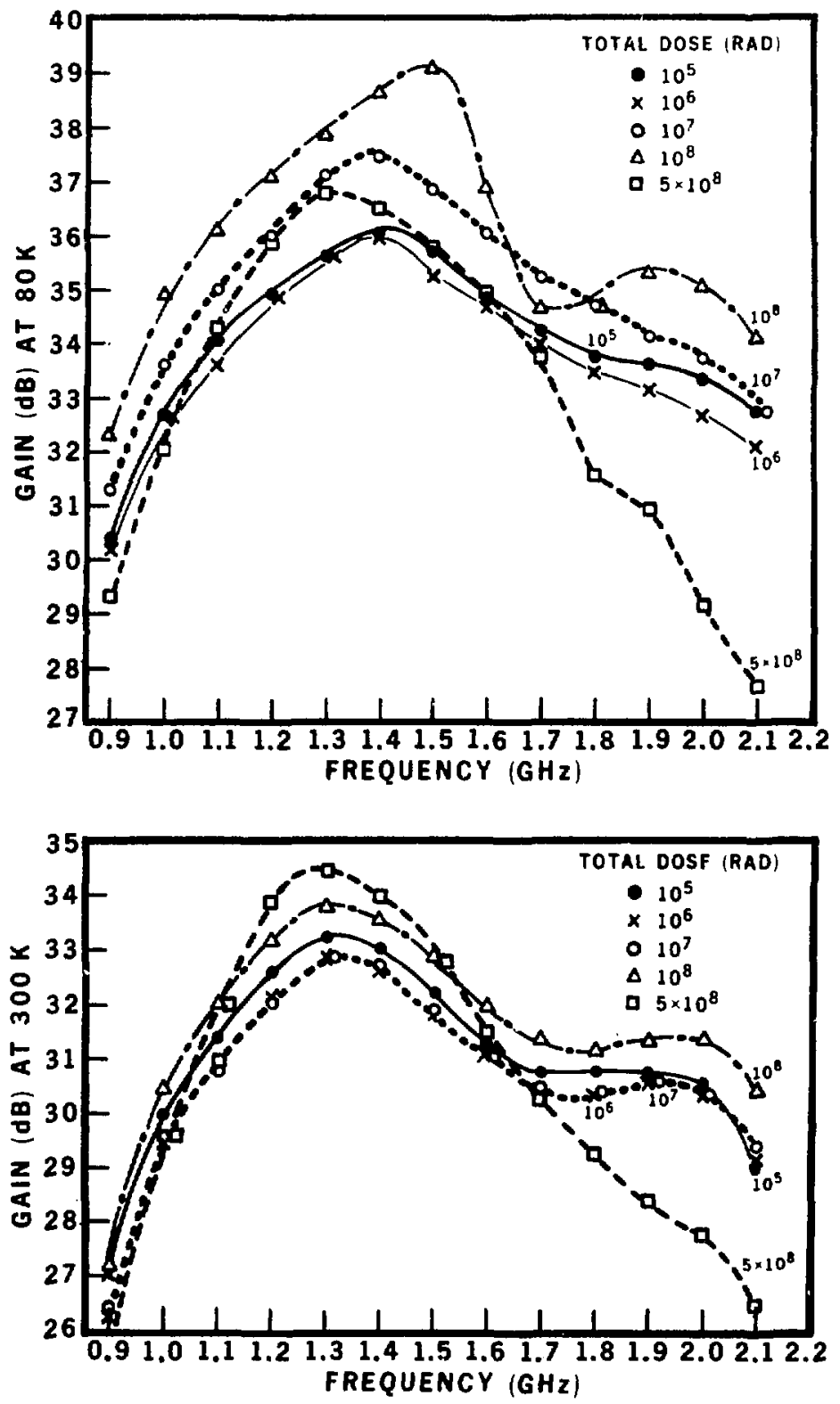

Figure 1: Gain Characteristic at $300 \mathrm{~K}$ and $80 \mathrm{~K}$ with the radiation dose as the variable.

XBL $871-77$ 

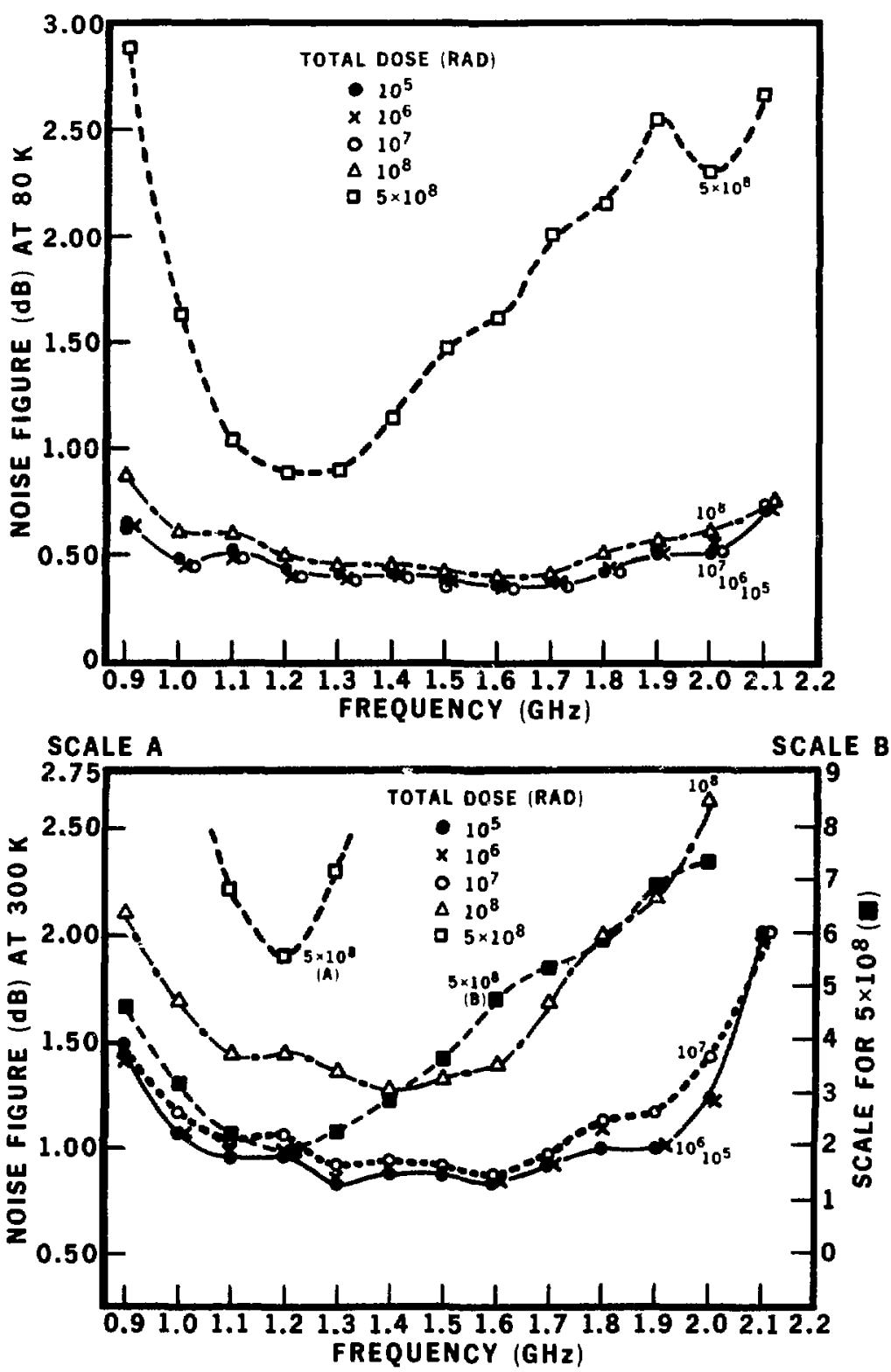

Figure 2: Noise Figure at $300 \mathrm{~K}$ and $80 \mathrm{~K}$ with the radiation dose as the variable.

XBL 871-78 